\title{
Inefficiency of equilibria in query auctions with continuous valuations
}

Citation for published version (APA):

Grigorieva, E., Herings, P. J. J., Müller, R. J., \& Vermeulen, A. J. (2009). Inefficiency of equilibria in query auctions with continuous valuations. METEOR, Maastricht University School of Business and Economics. METEOR Research Memorandum No. 024 https://doi.org/10.26481/umamet.2009024

Document status and date:

Published: 01/01/2009

DOI:

10.26481/umamet.2009024

Document Version:

Publisher's PDF, also known as Version of record

\section{Please check the document version of this publication:}

- A submitted manuscript is the version of the article upon submission and before peer-review. There can be important differences between the submitted version and the official published version of record.

People interested in the research are advised to contact the author for the final version of the publication, or visit the DOI to the publisher's website.

- The final author version and the galley proof are versions of the publication after peer review.

- The final published version features the final layout of the paper including the volume, issue and page numbers.

Link to publication

\footnotetext{
General rights Owners
rights.

- You may freely distribute the URL identifying the publication in the public portal. please follow below link for the End User Agreement:

www.umlib.nl/taverne-license

Take down policy

If you believe that this document breaches copyright please contact us at:

repository@maastrichtuniversity.nl

providing details and we will investigate your claim.
}

Copyright and moral rights for the publications made accessible in the public portal are retained by the authors and/or other copyright owners and it is a condition of accessing publications that users recognise and abide by the legal requirements associated with these

- Users may download and print one copy of any publication from the public portal for the purpose of private study or research.

- You may not further distribute the material or use it for any profit-making activity or commercial gain

If the publication is distributed under the terms of Article $25 \mathrm{fa}$ of the Dutch Copyright Act, indicated by the "Taverne" license above, 


\section{Maastricht University}

Elena Grigorieva, P. Jean-Jacques Herings, Rudolf Müller, Dries Vermeulen

I nefficiency of equilibria in query auctions with continuous valuations

RM/09/024

\section{METEOR}

Faculty of Economics and Business Administration Maastricht Research School of Economics

of Technology and Organization

\section{P.O. Box 616}

NL - 6200 MD Maastricht

The Netherlands 


\title{
Inefficiency of equilibria in query auctions with continuous valuations ${ }^{1}$
}

\author{
Elena Grigorieva, ${ }^{2}$ P. Jean-Jacques Herings, ${ }^{3}$ Rudolf Müller, ${ }^{4}$ and Dries Vermeulen ${ }^{5}$
}

\begin{abstract}
Query auctions are iterative auctions in which bidders have to select in each round an action from a finite set. We show that, when bidders have continuous valuations, any ex post equilibrium in an ex post individually rational query auction can only be ex post efficient when the running time of the auction is infinite for almost all realizations of valuations of the bidders. Thus, when valuations are drawn from a continuous probability distribution, efficiency can only be bought at the expense of a running time that is infinite with probability one. For two bidders we even show this to be true when we only require efficiency with probability one.
\end{abstract}

Keywords and Phrases: Query auctions, ex post equilibrium, efficiency.

JEL Classification Numbers: C72, D44.

\footnotetext{
${ }^{1}$ This is a revised version of METEOR Research Memorandum 06/17

2 e.grigorieva@ke.unimaas.nl. Department of Quantitative Economics, Maastricht University, P.O. Box 616, 6200 MD Maastricht, The Netherlands. The author acknowledges support by the Dutch Science Foundation NWO through grant 401-01-101.

${ }^{3}$ p.herings@algec.unimaas.nl. Department of Economics, Maastricht University, P.O. Box 616, 6200 MD Maastricht, The Netherlands. The author acknowledges support by the Dutch Science Foundation NWO through a VICI-grant.

${ }^{4}$ r.muller@ke.unimaas.nl. Department of Quantitative Economics, Maastricht University, P.O. Box 616, 6200 MD Maastricht, The Netherlands.

${ }^{5}$ d.vermeulen@ke.unimaas.nl. Department of Quantitative Economics, Maastricht University, P.O. Box 616, 6200 MD Maastricht, The Netherlands.
} 


\section{Introduction}

This paper concerns the sales of a single indivisible item to $n$ buyers by means of an auction, buyer $i$ having a private valuation $v_{i}$ for the item. ${ }^{1}$ In this setting the sealed-bid second price auction, or Vickrey auction, introduced by Vickrey [10] collects sealed bids, allocates to the bidder with the highest bid (if more than one, using a lottery), and sets the price equal to the second-highest bid. In equilibrium this auction solves the allocation problem in dominant strategies and awards the item to the bidder with the highest valuation.

The strategic properties of the Vickrey auction rely on exact communication of valuations between bidders and auctioneer. This is problematic when bidder's valuations are continuous and communication takes place via a digitized communication channel. Whatever language is used to communicate valuations, the number of expressible elements in any digitized language is at most countable. Thus, when bidder's valuations are continuous, no language suffices to communicate the amount of information needed to run the Vickrey auction.

For (to our knowledge) all digitally implementable auctions for the sale of a single indivisible item which have been proposed in the literature, it is known that they may allocate the item inefficiently. The English auction with a fixed bid increment for example is not efficient in this setting. Also David et al. [4] report on the inefficiency of English auctions with discrete bid levels when valuations are continuous. In the same setting Grigorieva et al. [5] show that $c$-bisection auctions allocate inefficiently in equilibrium.

In this paper we prove that a strong version of this fact-when valuations are continuous digitally implementable auctions allocate inefficiently in equilibrium - holds true in a wide class of auctions. We improve the basic observation in three ways. We prove that inefficiency inevitably occurs, ${ }^{2}$ for any equilibrium whose running time is finite with positive probability, within a wide class of digitally implementable auctions.

In the paper we first provide a workable definition of digitally implementable auctions in the form of query auctions. A query auction is an iterative auction in which bidders have to select in each round from a finite set of actions. We show that any query auction allocates inefficiently in equilibrium, unless one accepts the unrealistic phenomenon that the auction will last indefinitely - i.e. the auction runs an infinite number of rounds - for almost all realizations of valuations. In other words, in a model with continuous valuations any query auction that is

\footnotetext{
${ }^{1}$ We assume quasi-linear utilities.

${ }^{2}$ For two bidders we even show that inefficiency must happen with positive probability.
} 
efficient will necessarily have an infinite running time for almost all realizations of valuations, and is hence not a feasible option in any practical sense.

Related literature. Rothkopf and Harstad [9] study a model with continuous valuations where bidders are obedient and can only bid on a finite number of bid levels. They analyze how the choice of bid levels influences efficiency and revenue under the assumption of straightforward bidding by the bidders. Also Blumrosen and Nisan [1], Blumrosen et al. [2], and Blumrosen et al. [3] study a model where bidders have continuous valuations and a finite set of bid levels. They show that in their model truthful bidding is a dominant strategy equilibrium and derive bounds on the loss of welfare in equilibrium. Parkes [8] studies a model in which bidders are uncertain about their preferences and preference elicitation is costly. He shows that in such an environment ascending price query auctions can achieve better allocative efficiency than a sealed bid auction, using less elicitation of preferences.

\section{Preliminaries}

A single indivisible object is being sold to one individual within a set $N=\{1, \ldots, n\}$ of bidders by means of a deterministic auction. The set of actions of bidder $i$ is denoted by $F_{i}$. Write $F=\prod_{i} F_{i}$. The winner determination rule $w: F \rightarrow N$ decides for each profile $f=\left(f_{i}\right)_{i \in N}$ of actions in $F$ who the winner of the object is. The payment function $p: F \rightarrow \mathbb{R}$ determines for each profile $f$ of actions in $F$ the amount $p(f)$ the winner $w(f)$ has to pay to the auctioneer. A triplet $(F, w, p)$ is an auction.

Each bidder has a valuation $v_{i}$ for the item. Valuations are drawn from a non-degenerate interval $I$ and are assumed to be private information. Bidders have to decide in advance which action to choose for each valuation they might possibly have. Thus, a strategy of bidder $i$ is a function $s_{i}: I \rightarrow F_{i}$ stating that bidder $i$, when having valuation $v_{i} \in I$, will take action $s_{i}\left(v_{i}\right)$ in $F_{i}$. A vector $s=\left(s_{i}\right)_{i \in N}$ of strategies is called a strategy profile.

A realization $v=\left(v_{i}\right)_{i \in N}$ of valuations defines an ex post game $(F, w, p, v)$ with action space $F_{i}$ for bidder $i$ and payoff function $u_{i}\left(v_{i}\right): F \rightarrow \mathbb{R}$ defined by

$$
u_{i}\left(v_{i}\right)(f):= \begin{cases}v_{i}-p(f) & \text { if } i=w(f) \\ 0 & \text { otherwise }\end{cases}
$$

An action profile $f=\left(f_{i}\right)_{i \in N}$ is a Nash equilibrium of the ex post game $(F, w, p, v)$ if for every bidder $i$ and every action $g_{i} \in F_{i}$ of that bidder it holds that

$$
u_{i}\left(v_{i}\right)(f) \geq u_{i}\left(v_{i}\right)\left(f \mid g_{i}\right)
$$


where $\left(f \mid g_{i}\right)$ denotes the action profile where bidder $i$ chooses $g_{i}$ and every other bidder $j$ chooses $f_{j}$. A strategy profile $s=\left(s_{i}\right)_{i \in N}$ is an ex post equilibrium of the auction $(F, w, p)$ if for every realization $v=\left(v_{i}\right)_{i \in N}$ of valuations the action profile $s(v):=\left(s_{i}\left(v_{i}\right)\right)_{i \in N}$ in $F$ is a Nash equilibrium of the ex post game $(F, w, p, v)$.

Strategy $s_{i}$ is ex post individually rational if for every realization $v_{i}$ of the valuation of bidder $i$ and any profile $f$ of actions,

$$
u_{i}\left(v_{i}\right)\left(f \mid s_{i}\left(v_{i}\right)\right) \geq 0 .
$$

The auction $(F, w, p)$ itself is called ex post individually rational if every bidder has an ex post individually rational strategy in it. A strategy profile $s$ is called ex post efficient if for every realization $v=\left(v_{i}\right)_{i \in N}$ it holds that

$$
w(s(v)) \in \arg \max \left\{v_{i} \mid i \in N\right\} .
$$

DiRECT AUCTIONS An auction $(F, w, p)$ is called direct if $F_{i}=I$ for each bidder $i$. In other words, the action a bidder has to take in the auction is to report a valuation (not necessarily his true valuation). Since in a direct auction it is clear what the action spaces are, we will simply write $(w, p)$ to denote such an auction. A straightforward but important observation is that any strategy profile $s$ in $(F, w, p)$ automatically induces a direct auction $(w \circ s, p \circ s)$.

A direct auction $(w, p)$ is called a Vickrey auction if for every profile $r=\left(r_{i}\right)_{i \in N}$ of reported valuations in $I^{N}$ it holds that

$$
w(r) \in \arg \max \left\{r_{i} \mid i \in N\right\} \quad \text { and } \quad p(r)=\max \left\{r_{i} \mid i \neq w(r)\right\} .
$$

In a Vickrey auction bidding your valuation is a dominant strategy. If every bidder bids according to this strategy, the outcome is ex post efficient, and the winner pays an amount equal to the second-highest valuation.

A THEOREM OF GREEN AND LAFFONT In the next section we will use the following version of a Theorem by Green and Laffont, which shows under precisely which conditions a direct auction is a Vickrey auction (see Green and Laffont [7]).

Theorem 2.1 Let $(F, w, p)$ be an auction and let $s$ be a strategy profile in this auction. Suppose the following three conditions hold:

(a) the auction $(F, w, p)$ is ex post individually rational;

(b) the strategy profile $s$ is an ex post equilibrium of $(F, w, p)$;

(c) the strategy profile $s$ is ex post efficient in $(F, w, p)$.

Then the direct auction $(w \circ s, p \circ s)$ is a Vickrey auction. 


\section{The result}

We first specify the environment in which our result holds. A query auction is an auction in which the auctioneer sequentially offers bidders the opportunity to take one of a finite set of actions. Such an offer is referred to as a query. ${ }^{3}$ During the course of the auction each bidder may be, and usually will be, queried more than once.

Determination of winner and payment in a query auction are based exclusively on the actions taken by the bidders in response to the queries of the auctioneer. The auction ends as soon as both winner and payment are determined. The number of times a particular bidder is queried during the auction is not assumed to be bounded, and the auction may thus potentially take an infinite number of query rounds.

Now suppose we are given a query auction $(F, w, p)$ together with an ex post equilibrium $s=\left(s_{i}\right)_{i \in N}$ in this auction. Let $Z$ be the set of valuations $v=\left(v_{i}\right)_{i \in N}$ for which in the action profile $s(v):=\left(s_{i}\left(v_{i}\right)\right)_{i \in N}$ the auctioneer asks a finite number of queries before the auction ends. When the Lebesgue measure of the set $Z$ is equal to zero, we say that the query equilibrium $s$ almost always has infinite running time.

Theorem 3.1 Let $s$ be an ex post equilibrium in an ex post individually rational query auction. Suppose that $s$ is ex post efficient. Then s almost always has infinite running time.

Proof. Consider an ex post equilibrium $s$ in an ex post individually rational query auction $(F, w, p)$. Suppose that $s$ is ex post efficient. We show that $Z$ has Lebesgue measure zero. According to Theorem 2.1, the corresponding direct auction $(w \circ s, p \circ s)$ is a Vickrey auction. Now, for $i \in N$ and $k \in \mathbb{N}$, let $Z(i, k)$ be the set of valuations $v$ such that $(w \circ s)(v)=i$ and the auction ends after exactly $k$ rounds. Further, for $r \in \mathbb{R}$, let $Z(i, k, r)$ be the set of valuations $v \in Z(i, k)$ such that $(p \circ s)(v)=r$. Let $R(i, k)$ be the set of prices $r$ such that $Z(i, k, r)$ is not empty. Since the auction is deterministic, $R(i, k)$ is finite. Since $(w \circ s, p \circ s)$ is a Vickrey auction, we have for any $v$ and $i$ such that $(w \circ s)(v)=i$

$$
(p \circ s)(v)=\max \left\{v_{j} \mid j \in N \backslash\{i\}\right\}
$$

Thus

$$
Z(i, k, r) \subseteq \bigcup_{j \in N \backslash\{i\}}\left\{v \in I^{n} \mid v_{j}=r\right\},
$$

\footnotetext{
${ }^{3}$ Typically an "action" in a query auction takes the form of an answer to a query regarding the valuation of the bidder in question, such as "Is your valuation larger than 15 ?". In which case the response can be either "yes" or "no".
} 
and $Z(i, k, r)$ is contained in a set with Lebesgue measure 0. Finally

$$
Z=\bigcup_{i \in N} \bigcup_{k \in \mathbb{N}} \bigcup_{r \in R(i, k)} Z(i, k, r)
$$

and $Z$ is contained in the union of countably many sets of Lebesgue measure zero. Hence, also $Z$ has Lebesgue measure zero.

Thus, in an ex post individually rational query auction, ex post efficiency of an ex post equilibrium can only be bought at the expense of a running time of the auction that is infinite for almost all realizations. Consequently, when valuations are drawn from a continuous probability distribution and we want to construct a query auction that allocates efficiently ex post, we necessarily end up with a query auction that in equilibrium runs an infinite amount of time with probability one!

\section{Two bidders}

For two bidders we can sharpen our result somewhat. In the general case the requirement is that the ex post equilibrium $s$ allocates efficiently for any realization of valuations (that is, $s$ is ex post efficient). Then we can conclude that the running time is infinite for almost all realizations of valuations. For two bidders we only need to require that the ex post equilibrium $s$ allocates efficiently for a set of valuation pairs that has full Lebesgue measure to get the same conclusion that the running time must be infinite almost always.

Theorem 4.1 Let s be an ex post equilibrium in an ex post individually rational query auction. Suppose that the set of valuation pairs for which $s$ does not allocate efficiently has Lebesgue measure zero. Then s almost always has infinite running time.

Proof. Consider an ex post equilibrium $s$ in an ex post individually rational query auction $(F, w, p)$. Suppose that there is a valuation pair $\left(v_{1}, v_{2}\right)$ in $I \times I$ for which $s$ does not allocate efficiently. In view of Theorem 3.1 it suffices to show that the set of valuation pairs for which $s$ does not allocate efficiently has Lebesgue measure strictly larger than zero. Suppose w.l.o.g. that $v_{1}>v_{2}$ and that bidder 2 is the winner. Let $S$ be the set of pairs of valuations $\left(u_{1}, u_{2}\right)$ in $I \times I$ for which $v_{2}<u_{1}<v_{1}$ and $v_{2}<u_{2}<v_{1}$ and $u_{2}<u_{1}$. Because $s$ is an ex post equilibrium, it is straightforward to check that bidder 2 will also win the auction for any $\left(u_{1}, u_{2}\right) \in S$. Thus, the auction allocates inefficiently for any $\left(u_{1}, u_{2}\right) \in S$. Moreover, $S$ has Lebesgue measure strictly larger than zero. 
Corollary 4.2 Suppose that in an ex post individually rational query auction valuations are drawn from a probability measure $\mu$ with $\mu(E)=0$ for any set $E$ with Lebesgue measure zero. Let $s$ be an ex post equilibrium in the auction. Suppose that in equilibrium the auction allocates inefficiently with probability zero. Then the running time of $s$ in the auction is infinite with probability one.

Thus, suppose that we want to construct a query auction that allocates efficiently ex post, or even only efficiently ex post with probability one. Then we necessarily end up with a query auction that in equilibrium runs an infinite amount of time with probability one!

\section{Concluding remarks}

Auctions with discrete bid levels are examples of query auctions. Thus our result shows the inefficiency of for example the auction proposed in David et al. [4], as was already established by simulation. Our result also applies to the auctions studied in Grigorieva et al. [5].

However, to appreciate the generality of the result, note that the class of query auctions does include, but is by no means restricted to the class of auctions with discrete bid levels. In a query auction, the number of queries is not assumed to be bounded. Thus, the auction where digit by digit the precise binary representation of all bidders' valuations are queried and where the result is used to execute the Vickrey auction is also an example of a query auction. The full strength of the result lies in the observation that, even within this wide class of (individually rational) query auctions, efficiency (for two bidders even only efficiency with probability one) can only be bought at the expense of a running time of the auction that is infinite almost always. This is a much stronger result than the more straightforward observation that discrete bid level auctions are necessarily inefficient.

A second source of generality of the class of query auctions is the informational structure in the auction. Our result applies, irrespective of the information that bidders receive during the auction. The only requirement is that the bidders play an ex post equilibrium in the query auction given their information. Thus our result applies to auctions with perfect information and auctions with imperfect information alike.

Finally, our result is based on the observation that, for query auctions, the sets $R(i, k)$ as defined in the proof of Theorem 3.1 are countable at most. Therefore our result also holds in any class of auctions other than the class of query auctions for which the sets $R(i, k)$ are countable. 


\section{References}

[1] Blumrosen, L., and N. Nisan (2002), Auctions with severely bounded communication, in Proceedings of 43th Annual Symposium on Foundations of Computer Science, Vancouver, Canada, 406-416.

[2] Blumrosen, L., N. Nisan, and I. Segal (2003), Multi-player and multi-round auctions with severely bounded communication, in Proceedings of 11th annual European Symposium on Algorithms, Budapest, Hungary.

[3] Blumrosen, L., N. Nisan, and I. Segal (2007), Auctions with severely bounded communication, in Journal of Artificial Intelligence Research, 28: 233-266.

[4] David, E., A. Rogers, N.R. Jennings, J. Schiff, S. Kraus, and M.H. Rothkopf (2005), Optimal design of English auctions with discrete bid levels, in ACM Transactions on Internet Technology, $7(2): 2-34$.

[5] Grigorieva E., P.J.J. Herings, R. Müller, and D. Vermeulen (2006), The family of c-bisection auctions: efficiency and running time, METEOR research memorandum RM06019.

[6] Grigorieva E., P.J.J. Herings, R. Müller, and D. Vermeulen (2007), The private value single item bisection auction, in Economic Theory, 30: 107-118.

[7] Green J., and J.J. Laffont (1977), Characterization of satisfactory mechanisms for the revelation of preferences for public goods, in Econometrica, 45: 427-435.

[8] Parkes, D. (2005), Auction design with costly preference elicitation, in Annals of Mathematics and AI, 44, Special issue on the foundations of electronic commerce: 269-302.

[9] Rothkopf, M.H., and R.M. Harstad (1994), On the role of discrete bid levels in oral auctions, in European Journal of Operational Research, 74: 572-581.

[10] Vickrey W. (1961), Counterspeculation, auctions and competitive sealed tenders, in Journal of Finance, 16, 8-37. 